\title{
CROSS BORDER MIGRATION AND THE SPREAD OF INFECTIOUS DISEASES (HIV \& TB): A COMPARATIVE ANALYSIS OF NIGERIA AND BENIN REPUBLIC, 1999-2017
}

\section{Ezeabasili Ifeoma Ethel (Ph.D)}

Department of Political science Chukwuemeka Odumegwu University, Igbariam

Email: ie.ezeabasili@coou.edu.ng

\section{Cite this article:}

Ezeabasili I.E. (2021), Cross Border Migration and the Spread of Infectious Diseases (HIV \& TB): A Comparative Analysis of Nigeria and Benin Republic, 1999-2017. African Journal of Social Sciences and Humanities Research 4(3), 90104. DOI: 10.52589/AJSSHRZFEA6EUM.

\section{Manuscript History}

Received: 8 June 2021

Accepted: 3 July 2021

Published: 12 July 2021

Copyright $\odot 2020$ The Author(s). This is an Open Access article distributed under the terms of Creative Commons AttributionNonCommercial-NoDerivatives 4.0 International (CC BY-NC-ND 4.0), which permits anyone to share, use, reproduce and redistribute in any medium, provided the original author and source are credited.
ABSTRACT: Cross border migration is the movement of people across their national boundaries, it is a phenomenon that cuts across tribes, religions, and status, it is a universal phenomenon, the quest for individuals to meet their basic requirements which will enable them to live a life free from fear and wants, engenders these phenomena. This paper examines the relationship between cross-border migration and the spread of infectious diseases: HIV and Tuberculosis in Nigeria and the Benin Republic. This study utilized a secondary method of data collection. Classical migration theory was the theoretical framework on which the study was anchored. Using descriptive statistics and Pearson Correlation Coefficient, as a method of data analysis, the findings revealed that cross-border migration contributed to HIV transmission among women in Nigeria and the Benin Republic; and Tuberculosis incidence in the Benin Republic. This study concludes that cross-border migration plays an essential role in the spread of HIV in women in Nigeria and Benin Republic respectively; and Tuberculosis in the Benin Republic. Based on the findings the study recommends; that governments of both Nigeria and Benin Republic should establish mechanisms for the screening of migrants and returnees at the point of entry to know their health status and improve health facilities by; providing rapid testing equipment, mobile laboratories, and clinics, formulate policies that will address the rights of migrants, provide health workers with adequate protective machines.

KEYWORDS: Cross border migration, infectious diseases, migrants, Nigeria, Benin Republic, Human Security. 


\section{INTRODUCTION}

Cross-border migration is the movement of people across the boundaries of their States /nations. It is a universal characteristic of population distribution (Adeola \& Fayomi, 2012). Human security is a situation where the security of an individual becomes a priority in the international and national policy expert agenda. United Development Programme (UNDP), 1994 report posit that human security contains two complementary elements: 'Freedom from Fear' which includes threats arising from state-sponsored violence and war, Freedom from want' which includes threats arising from poverty, infectious diseases, economic recession etc (UNDP, 1994:24).

The inability of attaining these basic requirements that allow individuals to live their lives free from fear and want that drives migration

Before the advent of colonialism in West Africa, Cross border migration existed and was involuntary as people were forcefully taken away from their countries of origin as a result of the slave trade. During this era, many people were taken away from West Africa to advanced countries especially Europe and America to work in plantations over there (Darkwah \& Vertter, 2014). The post-independence era witnessed increased interaction and intensity of economic and political associations amongst states, to attain sustainable peace and security which is a prerequisite for socio-economic and political advancement. Over the years, this mindset shaped and guided, promoted, and led to the formulation of the ECOWAS Protocol. The ECOWAS Protocol was born out of the quest to have political, socioeconomic, and security cooperation that will promote trade, maintain peace, and protect the citizens of member states.

ECOWAS Protocol was established in 1979, the ECOWAS Protocol of free movement of persons, goods, and capital was established in 1979 (ECOWAS, 2006; Opanike, Adolojucad Adenipekun, 2005). The Protocol gives the citizens of various communities the right to movements and establishment of residence anywhere within the boundaries of member states (ECOWAS, 1979). Again, Nigeria and cultural fault-lines such as language and race are responsible for the changes in Cross border migration (Olawale, 2011, Blum, 2014 \& Dinshack \& Dantulani, 2018). For instance, the Egunard Ago (Yoruba) speaking people in the South, the Boriba (Borgwa) in the middle Belt, and the Fulani and Hausa in the north living along the border between two countries.

The quest for employment opportunities and greener pastures led to mobility within and across borders, especially rural migration because the cities attracted people within and outside the countries, while economically viable regions attracted migrants. In West Africa, countries such as Ghana, Nigeria, and Benin republic became the destination countries for cross border migration. Nigeria and Benin Republic are the most important hotspot for economic activities in the region; both economies relied on each other, resulting in cross-border contacts between them. Again, it is a major part of the Lagos-Abidjan transport and migration corridor; it represents a key doorway in the ECOWAS region. Also, the economic boom of the 1970s and 1980s further attracted people to Nigeria from the sub-region, this was short-lived with the deteriorating socioeconomic conditions and deepening poverty in the mid-1980s which invoked a wide variety of migration. Also, the introduction of the Structural Adjustment Programme (SAP) led to job crises in the labour market, creating sustained pressure for emigrants; hence Nigeria and Benin citizens began to look elsewhere across their borders for wage differentials, high income, better job opportunities, good living standards and access to 
Medicare, etc. However, there are series of controversies about the impact of human mobility on the countries of origin and the place of destination as well as migrants involved. For instance, Lagarde, Sachim Enel, Holmgram, Pison, and Piau (2003) argue that migration plays a significant role in the spread of infectious diseases. (HIV in West Africa) contrary to this view, Vignier \& Bouchaud (2018) averred that the role played by migrants in the transmission of infectious diseases is weaker than imagined. It is against this background that this paper examines the cross-border migration and the spread of infectious diseases: A comparative analysis of Nigeria and Benin Republic, 1999-2017.

\section{LITERATURE REVIEW}

Migration may also have health consequences on the migrant home country. Persons or individuals who emigrate in search of greener pastures may cause a brain drain in their country of origin this is because when individuals with technical skills have moved out en mass, this is likely to reduce the local infrastructures. This specifically impacts healthcare because there are usually economic benefits for the healthcare professional that migrate. Mejia, Royshon, and Pizurki (1979) argue that the mobility of health professionals from developing countries to developed ones widens the existing gaps in the global health workforce and that this can cause a deficiency in the provision of services in the developing countries. Again, Hagopian, Thompson, Fordyce, Johnson, and Heat (2004) assert that about 23\% of American Physicians received their medical training in the United States of America. About $64 \%$ of the foreigntrained physicians in the USA came from middle or low-income countries. Similarly, Glover, Gott, portes, price, Spencer, Loizillon, Srinivason (2001) and 13\% of nurses in the United Kingdom (U.K) were born abroad. Though countries of origin may benefit from income sent home, (e.g migrants wages sent home).

The harms it causes developing countries such as Nigeria and Benin Republic are far greater than the benefits. Again, there are also health implications of migration in the recipient countries. Some of the recipient countries are bothered about the spread of contagious diseases in migrants, and screening of migrants which infringes on the human rights of the migrants has been adopted to a large extent by various countries globally (Patterson, 2003). While some migrants may be fit and healthier than the population (The healthy migrant effect), other migrants may have pre-existing health challenges that can distort the local health facilities. For instance, a situation where older adults who usually need more health care, move to a warmer destination e.g Florida and Spain e.t.c this can pose a big strain on the host country health care system. In a related study, Kahn, Collison, Toolman, Wola, Garenne, and Clark (2003) posit that migration poses a threat to migrants' health as some jobs expose migrants to hazards, such as pneumoconiosis, tuberculosis and workplace disasters as in the case of factory workers. Increased movement of workers has also facilitated the spread of infectious diseases such as HIV (Lurie, 2000; \& Brummer 2002 as cited in Ratha, (2010) in their study on Health Consequences of Migration. Kahn et al (2003) in their study on Health Consequences on migration argued that sexually transmitted and contagious diseases have more potential to spread among migrants as well as their partners back in their home countries.

Furthermore, highly skilled emigration / 'brain-drain' can mean loss of public resources invested in education; and this can reduce the home country's productive capacity and stiffen the business atmosphere especially in developing economies. The movement of highly skilled 
professionals can be of immense importance in the health and educational sectors in small countries that suffer a shortage of health personnel (Docquier, et al, 2010). In a similar vein, Dustmann, Fadlon \& Weiss (2010), argued that return migrants can lead to 'brain gain. The study by Whaba (2007) concurred by stating that migrants bring back home, skills they have acquired, and wages paid, which they use for the betterment of their home communities. More so, the UNDP (2009), also, reiterated that returning migrants may also bring health-improving practices they have acquired back home, such as practices like drinking clean water, better sanitation and a good living environment. Despite the fears about the drastic consequences of brain drain on health, the shortage of health workers in Africa has nothing to do with international migration by the fragmented labour market and inadequate public funding (UNDP, 2009).

There are a series of controversies surrounding the relationship between cross border migration and the spread of diseases. However, empirical findings have divided opinion over its impact. For instance, the findings of Pison et al (1993) on seasonal migration: A risk factor for HIV infection in rural Senegal; and Tamins, Hallemarian, Mitike and Haider (2011) on HIV-related behaviour amongst migrants and Non-migrants in rural Ethiopia are indicative of showing that cross border migration plays a key role in the transmission of diseases. Similarly, Lagarde, Sachim, Holmgren Pison and Piau (2003) investigated the nexus between mobility and the spread of the Human Immunodeficiency virus into rural areas of West Africa using descriptive statistical analysis. The findings revealed a similar result with the above findings on Tamins et al (2011). In another study on Risk Factors for HIV infections among women in Carleton-Ville, South Africa; Zuma, Gouws, Williams, and Lurie (2003) examined the relationship between migration and HIV transmission on women, using survey data. Their study found out that migration increases the chances of HIV infection. The works of Sagguri, Mohapatra, Sabarwal, Ghosh, and Johri (2012) on male out-migration: A risk factor for the spread of HIV Infection among married men and women in rural India. The finding revealed that the occurrence of HIV is higher among men with migration history and also higher for women with migrant husbands. Collaboratively, Voeten, Vissers, Gregson, Zaba et al (2012) examined the relationship between in-migration and HIV prevalence in Urban Sub-Saharan Africa using linear regression analysis, their study found out that there is a strong association between migration and the spread of HIV for women. In related works, Abdo, Karim, (1997); Crush, William, Gouws (2005); Darks Collinson, Kahn, Durllinge and Tollman (2005), Mmbaga, Leyna, Hussain et al (2008) investigated the role migration plays in the spread of HIV diseases. Their findings revealed that migration significantly increases the prevalence of HIV Infections and Tuberculosis deaths. Contrary to these findings the studies of Philip, Vanlandingham, MandaFaylor, Hans-Peter et al (2016) on Migration and HIV Infection in Malawi. Luries, Williams Zuma, Mkaya, Mwamburi et al (2016) on the Impact of Migration on HIV transmission in South Africa and Isdory, Murei and Sumpter (2003) on the Impact of Human Mobility on HIV transmission in Kenya. Their findings revealed that migration has little or no effect on the spread of diseases such as HIV, and that migration is an Independent risk factor for HIV Infection, that the high prevalence is partly due to the selection of HIV positive Individuals into migration. Also, their finding revealed that HIV was found among rural women while the migration status of their partners was not a major risk factor for HIV, but that women lack access to adequate prevention and intervention mechanism, irrespective of the migration status of their partners. 
Again, the empirical studies by Pescarini, Simonsen, Ferrazoli, Rodrigues, Oliveira, Waldman and Houban (2018) investigated the impact of growing migration on the pattern of tuberculosis; in Sao Paulo Brazil. Using descriptive statistics, the study revealed that TB transmission is more common among Brazilian drug users (high-risk groups), but found limited transmission from migrants to Brazilians in central areas of Sao Paulo. On the contrary, Kristensen, Lillebaek, Petersen, Hargreaves, Neilums, Friedland, Andersen, Ravn and Norredam (2019) examined tuberculosis incidence among migrants and Danish-born from 1993 - 2015, using descriptive statistical analysis. The study found out that migrants had a significantly higher TB incidence when compared with the Danish-born. The study of Ponticiello, Simonetti, Ortolani, Malerba, and Sanduzzi (2005) examined tuberculosis incidence and its relationship with socioeconomic status and immigration in Naples. Using multivariate Poisson regression analysis, the study revealed, that immigrant has high risk of tuberculosis, but that the variation in tuberculosis incidence in Naples to a large extent is as a result of deprivation rather than immigration. In a related study, Alderidge, Zenner, White, Willianson, Muzyamba, Sharon, Mosca, Thomas, Lailor, Abubakar, and Hayward, (2016) examined tuberculosis in migrants moving from high-incidence to low-incidence countries, using a population-based cohort study of 519955 migrants entering England, Wales and Northern Ireland. The study indicated that migrants from countries with a high incidence of tuberculosis scanned before entry to lowincidence countries pose a negligible risk of onward transmission but are at high risk of tuberculosis. In a similar vein, Farah, Meyer, Heidel, and Blune, (2005) investigated the longterm risk of tuberculosis among immigrants in Norway using immigrants from Africa, Asia, Vietnam, Pakistan, former Yugoslavia, and Somalia. The study employed descriptive statistics, and the findings indicated that immigrants remain at a high risk of Tuberculosis infection many years after migration. The study further recommended that screening for Tuberculosis on arrival should be encouraged, and preventive measures for those with TB infection should be strengthened. In a related study, Eiset and Wejse (2017) reviewed the risk of infectious diseases connected to migration. The result revealed that the susceptibility of refugees and asylum seekers for tuberculosis is attributable to poor living conditions during and post-migration, cases where there is a high degree in refugee populations, there is very little risk of transmission to autonomous populations.

In a related study, Vignier and Bouchaud (2018) examined the relationship between migration and emerging infectious diseases using Descriptive Statistical Analysis. The study found out that the risk appears low for emerging infectious diseases (EIDs) or very low for high-risk emerging infectious diseases, but higher for Multidrug-Resistant Enterobacteriaceae (MRE) carriage with little consequences. Also, the role played by migrants are weaker than imagined, migrants could play a role in transmitting multidrug-resistant Enterobacteriaceae if it is not well managed. The works of Tuite, Thomas-Bachli, Acosta, Bhatia, Huber, Petrasek, et al (2018) investigated the infectious disease implications of large-scale migration of Venezuelan nationals. Using passenger itinerary data of the international air transport association. The result suggests that the outbreaks of measles, diphtheria, and malaria have been reported across Venezuelan and other infectious diseases such as HIV and tuberculosis are resurgent; changes in migration in response to the crisis are apparent with the increased number of Venezuelans living overseas. Despite the long-distance, migrants may travel internationally, outbreaks of diseases linked with Venezuelan migrants were a result of countries' proximities to Venezuela. The study further recommends that it is important to understand where international migrants are coming from and relocating to, given the relationship between migration and the spread of infectious diseases. 
The works of Adair and Nwaneri (1999) examined communicable disease in African Immigrants in Minneapolis using data obtained from immigrants chart of 102 patients who had emigrated from Africa in the last five years, the immigrants were from 12 countries in Africa namely, Nigeria, Somalia, Ethiopia, Kenya, Togo Cameroon, Libya, Egypt, Zaire, Rwanda and Sierra Leone, $52 \%$ of the patient had tuberculosis $14 \%$ had hepatitis B. The finding indicated that communicable disease is prevalent among African immigrants despite their healthy physical appearance and a long stay in the United States.

Contrary to the above, findings, Castelli and Sulis (2017) investigated the relationship between migration and infectious diseases in Europe. Using scientific literature, the study found out that infectious disease amongst migrants has an insignificant impact on European epidemiology.

\section{Theoretical Framework}

Human mobility does not only occur due to wage differences, as Neo-classical economists tend to believe, as a means of International price equalization between rich and poor regions but also there are other factors identified in the form of push and pull factors: Situation Oriented Approaches (Push-Pull Hypotheses). This approach was propounded by Lee (1966). He used this approach to explain the unpredictable nature of migrants. According to him, the most significant factors in migration are Push-pull factors. Here, the pessimistic factors in the place of origin are called the Push factors while the positive ones that attract migrants to the destination place are called the Pull factors, Lee (1966) further posit that the decision to move and the process of movement is influenced by factors associated with the areas of origin, destination, intervening factors, personal factors and variation in the economy. Push factors such as natural disasters, civil wars, violent conflict, poor wages, political repression, low wages, poor remuneration, drought, and famine, etc. have forced millions of people to move from their home country to others countries. While the Pull factors include: better employment opportunities, high standards of living, a better educational system, good basic infrastructures, good healthcare facilities, better wages, etc. all of which attract people from their country of origin to the host country.

This approach has become the dominant approach in the migration literature; this is because it is more comprehensive, hence it incorporates both the important factors that have an impact on migration decision-making and is also able to integrate other theoretical insights (De-Haas, 2010).

\section{Methodology}

This study employed secondary data collected from the World Bank development index, International organizations for Migration, World Health organizations, Journals Periodical, working papers and reports etc. Data collated were analyzed using descriptive statistics and Pearson correlation coefficient. 


\section{DATA ANALYSIS}

\section{The trend in Cross Border Migration and the spread of disease in Nigeria and Benin}

\section{Republic}

Descriptive Analyses of the relationship between Cross Border Migration and Spread of Infectious Diseases (HIV, Tuberculosis) in Nigeria and Benin Republic.

Table 1.1: Cross Migration and prevalence of HIV for (Male and Females) in Nigeria and Benin

\begin{tabular}{|l|l|l|l|l|l|l|l|l|}
\hline & \multicolumn{9}{|c|}{ Nigeria } & \multicolumn{5}{c|}{ Benin } \\
\cline { 2 - 9 } & $\begin{array}{c}\text { Migra } \\
\text { tion } \\
\text { of HIV for } \\
\text { male }\end{array}$ & $\begin{array}{c}\text { Prevalence } \\
\text { of HIV for } \\
\text { female }\end{array}$ & $\begin{array}{c}\text { Incidence } \\
\text { of Tuber } \\
\text { culosis }\end{array}$ & $\begin{array}{c}\text { Migra } \\
\text { tion }\end{array}$ & $\begin{array}{c}\text { Prevalence } \\
\text { of HIV for } \\
\text { male }\end{array}$ & $\begin{array}{c}\text { Prevalence } \\
\text { of HIV for } \\
\text { female }\end{array}$ & $\begin{array}{c}\text { Incidence } \\
\text { of } \\
\text { Tuberculosis }\end{array}$ \\
\hline 1999 & -0.10 & 1.2 & 3.3 & 219 & 0.02 & 0.2 & 1.2 & 81 \\
\hline 2000 & -0.08 & 1.3 & 3.3 & 219 & 0.21 & 0.3 & 1.2 & 86 \\
\hline 2001 & -0.13 & 1.4 & 3.2 & 219 & 0.33 & 0.4 & 1.2 & 83 \\
\hline 2002 & -0.13 & 1.6 & 3 & 219 & 0.34 & 0.5 & 1.1 & 80 \\
\hline 2003 & -0.16 & 1.8 & 2.8 & 219 & 0.34 & 0.5 & 1 & 78 \\
\hline 2004 & -0.17 & 2.1 & 2.6 & 219 & 0.45 & 0.6 & 0.9 & 75 \\
\hline 2005 & -0.09 & 2 & 2.5 & 219 & 0.22 & 0.6 & 0.9 & 73 \\
\hline 2006 & -0.21 & 2.3 & 2.3 & 219 & -0.53 & 0.6 & 0.8 & 71 \\
\hline 2007 & -0.20 & 2.3 & 2.1 & 219 & -0.58 & 0.6 & 0.7 & 69 \\
\hline 2008 & -0.20 & 2.3 & 2 & 219 & -0.52 & 0.5 & 0.7 & 69 \\
\hline 2009 & -0.20 & 2.3 & 1.9 & 219 & -0.50 & 0.5 & 0.6 & 69 \\
\hline 2010 & -0.15 & 2.2 & 1.8 & 219 & -0.46 & 0.4 & 0.6 & 68 \\
\hline 2011 & -0.20 & 2.1 & 1.8 & 219 & -0.47 & 0.4 & 0.6 & 67 \\
\hline 2012 & -0.18 & 1.9 & 1.7 & 219 & -0.43 & 0.4 & 0.6 & 66 \\
\hline 2013 & -0.22 & 1.8 & 1.7 & 219 & -0.32 & 0.3 & 0.6 & 64 \\
\hline 2014 & -0.19 & 1.6 & 1.7 & 219 & -0.21 & 0.3 & 0.6 & 61 \\
\hline 2015 & -0.19 & 1.5 & 1.7 & 219 & -0.12 & 0.3 & 0.6 & 60 \\
\hline 2016 & -0.07 & 1.4 & 1.6 & 219 & -0.10 & 0.3 & 0.6 & 59 \\
\hline 2017 & -0.17 & 1.3 & $n a$ & 219 & -0.09 & 0.2 & 0.6 & 58 \\
\hline
\end{tabular}

Key: $n a=$ not available

Source: World Development Index, (2018) edition.

Three variables for diseases are shown in Table 1. They include HIV prevalence for males (\% ages 15-24), HIV prevalence for females (\% ages 15-24), the incidence of Tuberculosis (TB). There is no data for the Ebola virus. The incidence of TB is defined as the number of new and relapsed TB cases in a given year, expressed per 100,000 populations. 
African Journal of Social Sciences and Humanities Research

ISSN: 2689-5129

Volume 4, Issue 3, 2021 (pp. 90-104)

www.abjournals.org

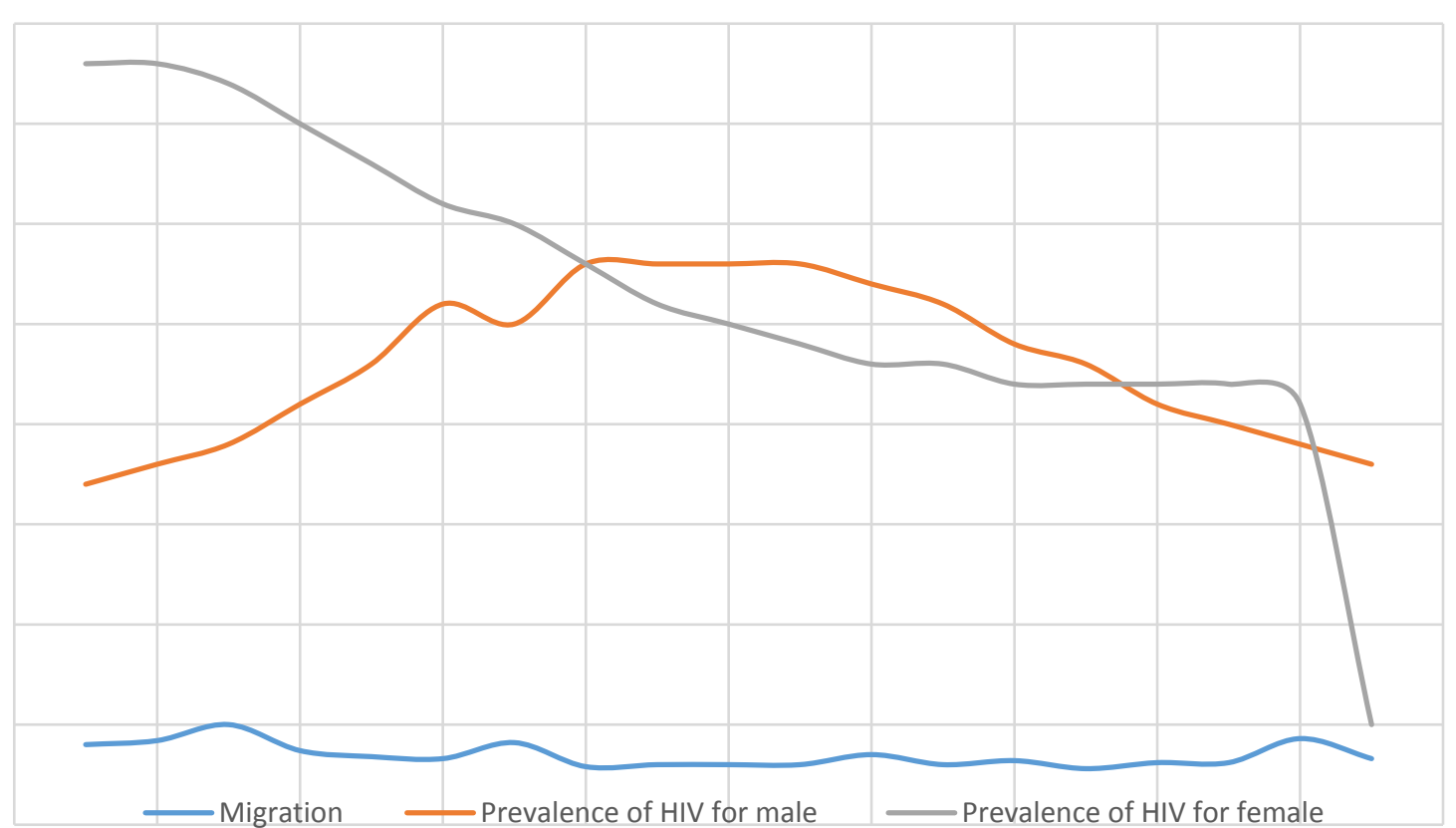

Figure 1.1: Trend analyses of the prevalence of HIV (Male and Females) in Nigeria

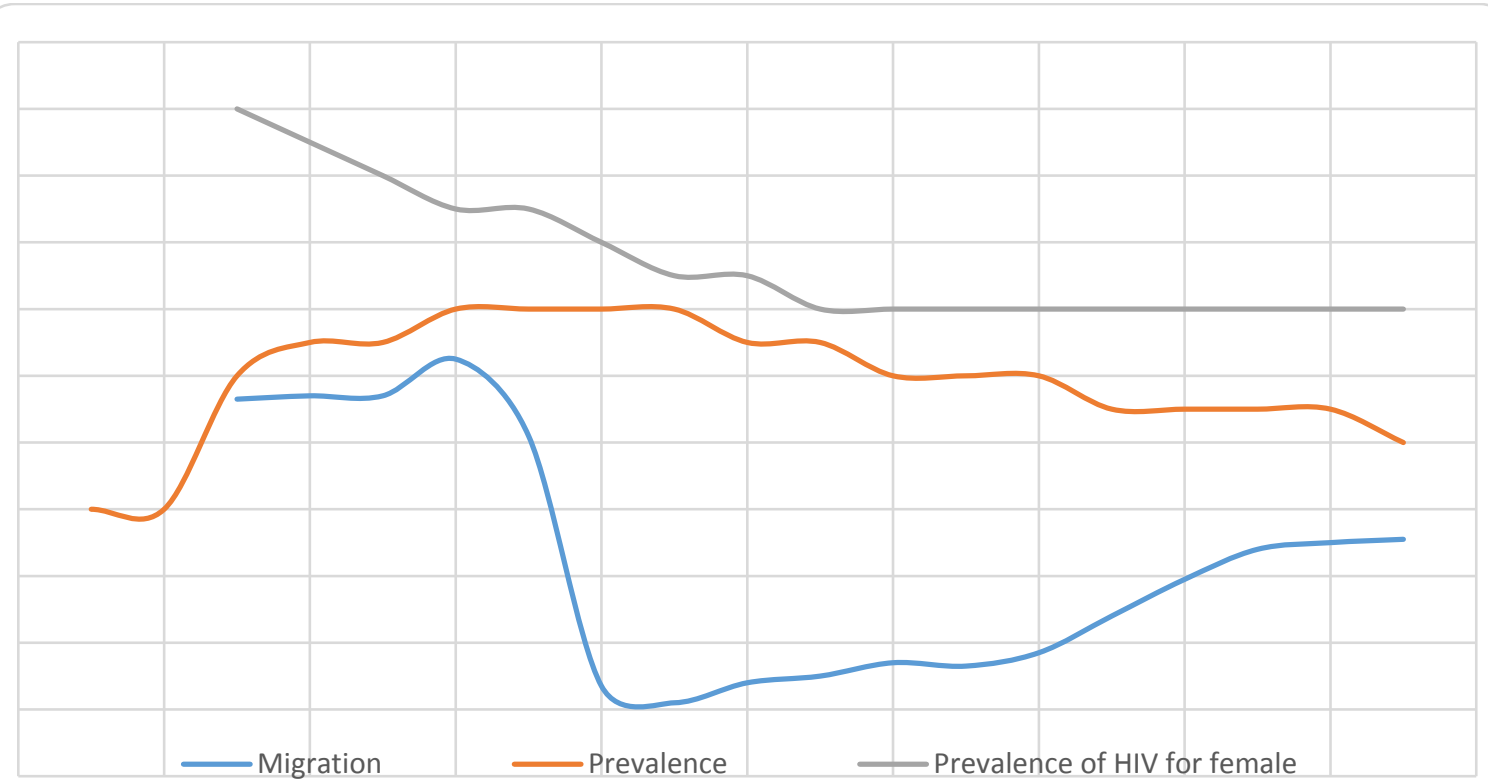

Figure 1.2: Trend analyses of the prevalence of HIV (Male and Females) in Benin Republic 
The graphs in Figures 1.1 and 1.2 are used to show the trend of the annual movement of net migration and HIV prevalence (Males and Females) for Nigeria and the Benin Republic, respectively.

In Figure 1.2, the trend in the annual prevalence of HIV for Females in Nigeria witnessed was at its peak between 1999 and 2000. From 2000, it had a steady plunge till 2016 where it was $1.6 \%$. For the Males, the prevalence was relatively low at the beginning of 1999 and grew as that of the females declined until the prevalence equalled in 2006 at the rate of $2.4 \%$. These trends imply that the scourge of prevalence of HIV for females was high in the early periods of 1999 and 2000, but received adequate attention that saw to its control and eventual reduction in the spread. Despite the control, the epidemic nature of HIV engendered quick transmissions to the male's counterpart. This trend did not follow the changes in net migration across Nigeria. This suggests that cross border migration for Nigeria may not be associated with health security.

In Figure 1.1 the trend showed several opposite directional flows of events in the prevalence of HIV and net migration in the Benin Republic. From 1999 to 2004, the trend was on the increase while net migration was on a steady decrease. While a gradual decrease in HIV especially for females continue, like that of the males rises while net migration steeped from 2004 through 2007 into negative trends where it remained until 2017. From 2010, the spread of HIV maintained a steady level trend for both Females and Males while net migration oscillated over time within the negative bounds.

These swings suggest a negative relationship between cross border migration and the spread of disease for Benin citizens.

\section{Cross border Migration and Tuberculosis prevalence for Nigeria and Benin}

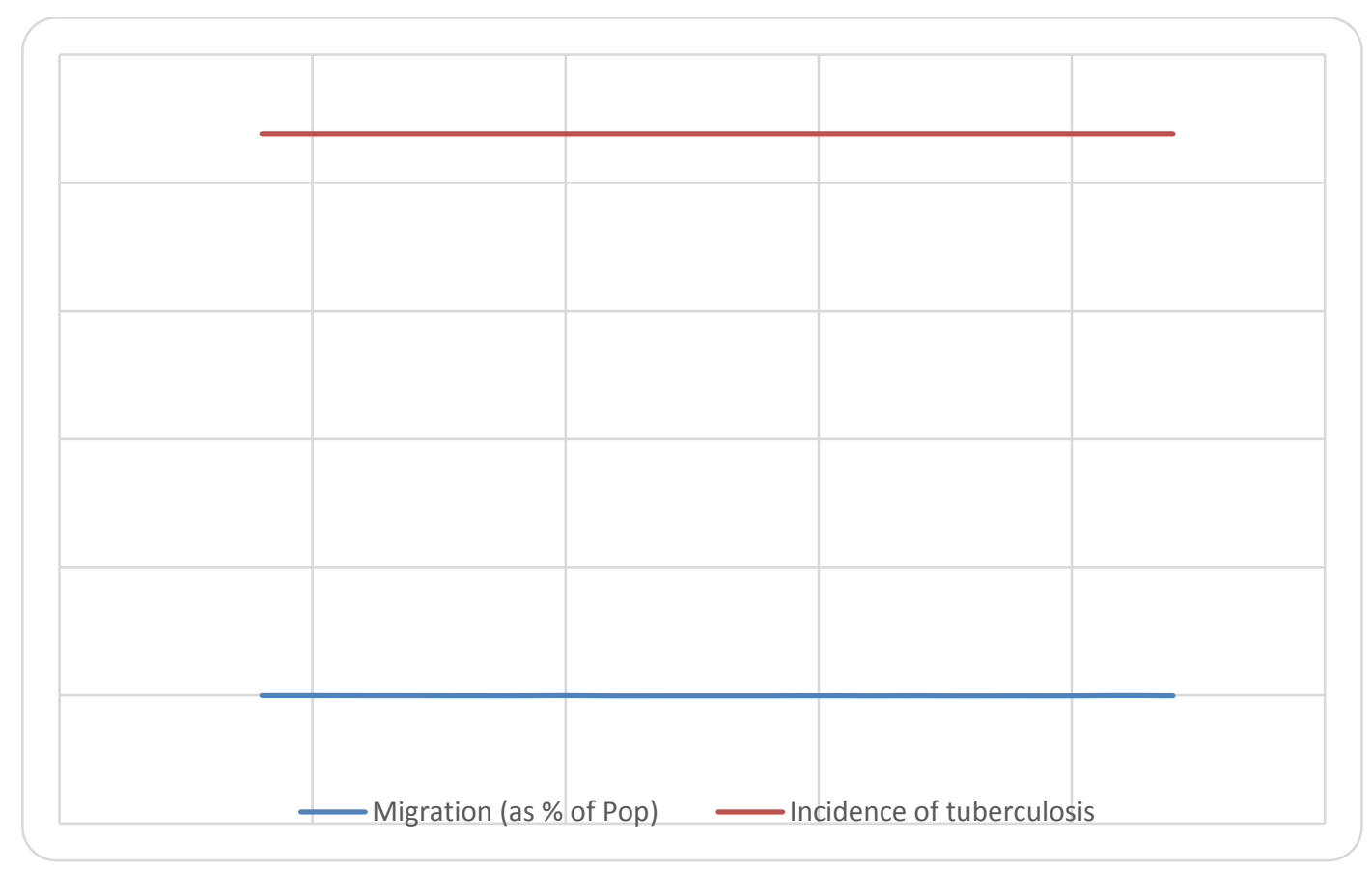

Figure 1.3: Trend analyses of the incidence of tuberculosis in Nigeria 


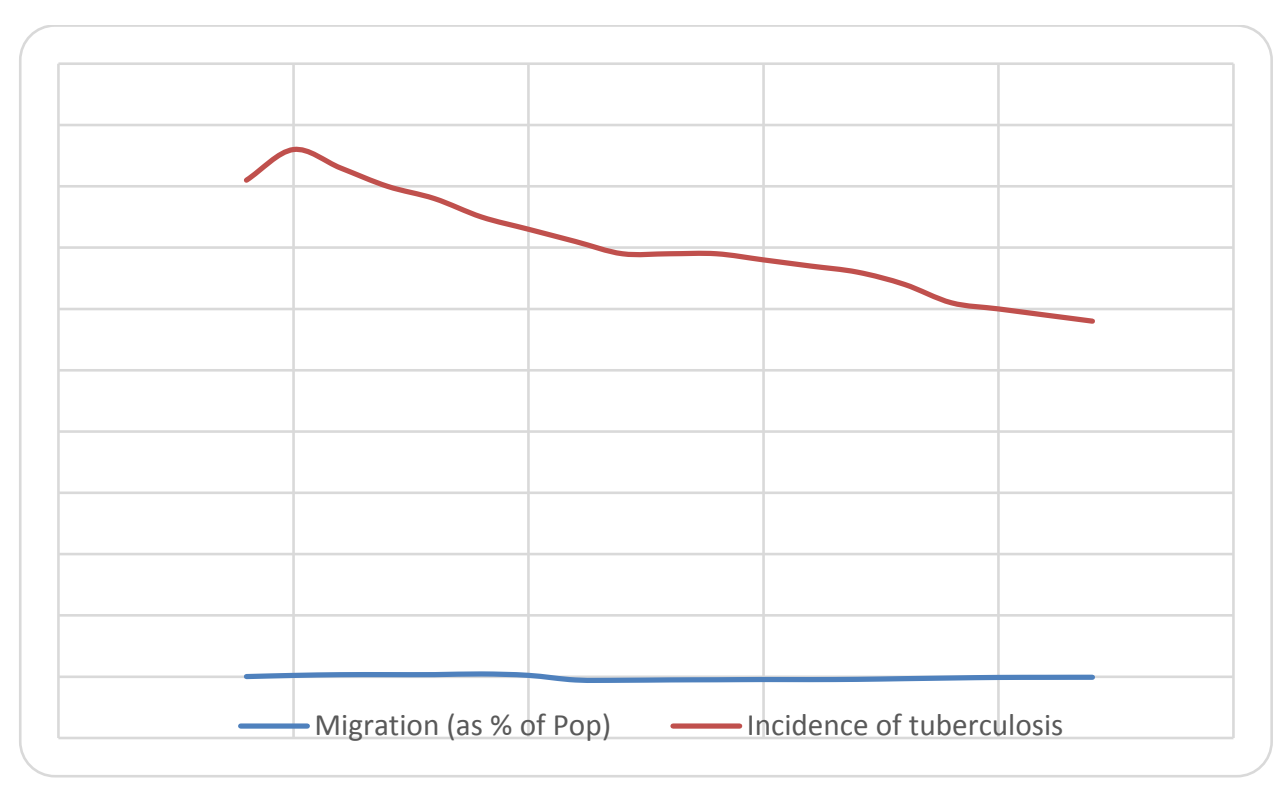

Figure 1.4: Trend analyses of the incidence of tuberculosis in Benin

The trend line of TB and migration for Nigeria in figure 1.3 maintained seemingly straight lines. This suggests constancy of effects. This means that a unit change in one variable may not influence the other variables to change. This implies that cross border migration does not contribute to the incidence of TB in Nigeria.

On the other hand, the case of Benin in figure 1.4 showed shifts in the movement of TB incidence over time. With a relatively stable movement in the cross border migration for the Benin Republic, the values for TB moved upwards from 1999 through easily 2000s and then dived steadily downward till present (2017) date of study coverage. This, however, suggests that cross border migration is not responsible for the incidence of TB in the Benin Republic.

\section{Testing of Hypotheses}

Ho: Cross border migration does not contribute to the spread of diseases in Nigeria and Benin Republic.

Table 1.2: Results of the correlation analyses between cross border migration and spread of diseases in Nigeria and Benin

\begin{tabular}{|c|c|c|c|}
\hline & & $\begin{array}{lr}\text { Cross } & \text { Border } \\
\text { Migration } & \text { in } \\
\text { Nigeria } & \end{array}$ & $\begin{array}{lr}\text { Cross } & \text { Border } \\
\text { Migration in } & \text { Benin } \\
\text { Republic } & \end{array}$ \\
\hline $\begin{array}{l}\text { Prevalence of HIV for } \\
\text { male } \\
\text { Prevalence of HIV for } \\
\text { female }\end{array}$ & $\begin{array}{l}\text { Pearson Correlation } \\
\text { Sig. (2-tailed) } \\
\text { N } \\
\text { Pearson Correlation } \\
\text { Sig. (2-tailed) } \\
\text { N } \\
\text { Pearson Correlation }\end{array}$ & $\begin{array}{l}-.588^{* *} \\
.008 \\
19 \\
.438 \\
.061 \\
19 \\
\mathrm{~b}\end{array}$ & $\begin{array}{l}-.018 \\
.940 \\
19 \\
.727^{* *} \\
.000 \\
19 \\
.565^{*}\end{array}$ \\
\hline
\end{tabular}


African Journal of Social Sciences and Humanities Research

ISSN: 2689-5129

Volume 4, Issue 3, 2021 (pp. 90-104)

www.abjournals.org

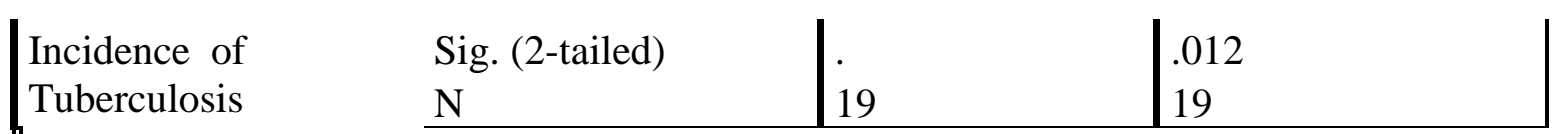

**. Correlation is significant at the 0.01 level (2-tailed).

*. Correlation is significant at the 0.05 level (2-tailed).

b. Cannot be computed because at least one of the variables is constant.

In the coefficient of correlation for cross border migration and spread of disease (Table 1.2), using the HIV prevalence revealed that the result for the males was -0.588 for Nigeria and 0.018 for the Benin Republic. For the females, the HIV, cross border migration coefficients are 0.438 for Nigeria and 0.727 for the Benin Republic. This means there is a moderate negative and very weak negative correlation between HIV prevalence for Males and net migration in Nigeria and Benin, respectively. This implies that increasing cross border migration engenders decreased HIV prevalence for males. However, the reverse for the females which showed an increasing HIV prevalence with opening (increased) migration. Thus, there is a positive relationship between cross border migration and HIV prevalence among women in both Nigeria and Benin.

For Tuberculosis, there was no correlation result for Nigeria owing to the constant nature of the data, however; Benin revealed a moderate (.565) positive association. This suggests that increased migration would eventually result in an increased incidence of Tuberculosis in Benin.

\section{DISCUSSION OF RESULT ON CROSS BORDER MIGRATION AND THE SPREAD OF HIV IN NIGERIA AND BENIN REPUBLIC}

The above in figure 1.3, shows a gender difference in the rate of prevalence of HIV infection. From 1999 through 2005 the prevalence was higher for women than men in Nigeria. Women recorded $3.3 \%$ in $2001,3 \%$ in $2002,2.8 \%$ (2003), $2.6 \% 2004,2.5 \%$ in 2005 . It equalized in the year 2006 with $2.3 \%$ for both males and females. From 2006, it had a steady plunge through 2006 where it was $1.6 \%$. This suggests that the spread of HIV was higher in women between 1999 and 2006 but probably have received adequate care that contained the spread. This trend implies that the prevalence of HIV is higher among women in Nigeria although the status of their partner is not known. This trend did not tally with the net changes in migration across Nigeria. This indicates that cross border migration for Nigeria may not have been linked with the spread of HIV.

In figure 1.4, HIV prevalence Benin Republic was higher for women than the men, from 1999 through 2017, $1.2 \%$ from 1999 and 2001, $1.1 \%$ in 2002, $1 \%$ in 2003, $0.9 \% 2004 \& 2005 ; 0.7 \%$ $0.8 \%$ in $2006,2007 \& 2008,0.6 \%$ from 2008 through 2017 while their male counterparts at each point was lower with result $0.2 \%$ in $1999,0.3 \% 2000,0.4 \%$ in $2001,0.5 \% 2002,0.5$ in 2003, 0.6\% from 2004 and 2007, 0.3\% from 2013 through 2017. This result suggests that the prevalence of HIV transmission was higher in women than men in Benin Republic.

The trend also showed a parallel flow of events in the prevalence of HIV and net migration in the Benin Republic. From 1999 to 2004, the trend was on the increase while net migration maintained a steady decrease, while there was a gradual decrease in HIV for women, again, that of the male rises while net migration becomes steeped from 2004 through 2007 into a 
negative trend and it remained till present. From 2010, the spread of HIV maintained a steady trend for both females and males while net migration fluctuates over time within negative bounds. This fluctuation suggests a negative relationship between cross border migration and the spread of diseases for Benin citizens. This implies that cross border migration does not contribute to the spread of HIV to Benin citizens. These results for Nigeria and the Benin Republic concerning the trend of net migration flow and HIV prevalence are consistent with the findings of Isdory Murelthi and Sumpter (2015) whose findings revealed that mobility between regions had little or no significant impact on the total increase in HIV cases. From table 1.2, the coefficient correlation for cross border migration and the spread of HIV using HIV prevalence, the result indicates -0.588 for Nigerian males and -0.18 for Beninese males. This suggests that there is a moderate negative and very weak negative correlation between HIV prevalence for males and net migration in Nigeria and the Benin Republic respectively. While the female HIV and cross border migration coefficients are 0.438 for Nigeria and 0.727 for the Benin Republic. The finding suggests that there is a positive correlation between HIV prevalence and net migration for females in Nigeria (Insignificant) and the Benin Republic. This implies that increasing cross border migration increases HIV prevalence in women for Nigeria and Benin Republic. This result in line with the findings of Voeten, Vissers, Gregson, Zaba, White, Devlas \& Habbema, (2012), whose findings indicated that there is a strong association between migration and HIV prevalence in women. This suggests that migration explains most of the differences in the spread of HIV in gender.

Findings: The correlation coefficient for cross border migration and HIV prevalence for males is -0588 and -018 for Nigeria and Benin Republic respectively. Also, the correlation coefficient for cross border migration and HIV for females is 0.438 and 0.727 for Nigeria and Benin Republic respectively. This suggests that cross border migration does not contribute to the spread of HIV for males in Nigeria and the Benin Republic respectively but there seems to be a positive relationship between cross border migration and HIV prevalence among females in Nigeria and the Benin Republic respectively. This implies that cross border migration contributes to the spread of HIV among women in Nigeria and Benin Republic. Secondly, the correlation coefficient for cross border migration and Tuberculosis in the Benin Republic is 0.565; this revealed a moderate positive association between the variables. This suggests that cross border migration contributes to the incidence of Tuberculosis in the Benin Republic. There was no correlation result for Nigeria owing to the constant nature of the data.

\section{CONCLUSION AND RECOMMENDATIONS}

The study concludes that cross border migration contributed to the spread of infectious diseases in Nigeria and Benin Republic. The government of both Nigeria and Benin Republic should establish mechanisms for the screening of migrants and returnees at the points of entry to know their health status and improve health facilities by; providing rapid testing equipment, mobile laboratories, and clinics; create programs that supports the sensitization of migrants and returnees, most importantly formulate policies that will address the rights of migrants and the kind of services to which they will have access; provide health workers with proper protective machines. 


\section{REFERENCES}

Adair, R. (1999). Communicable disease in African Immigrants in Minneapolis. ARCH INTERN MED, vol 159(1): 83 - 85 .

Adeola ,G.L. \& Fayomi, O. (2012). The Political and Security Implications of Cross Border Migration between Nigeria and Her Francophone Neighbours. International Journal of Social Science Tomorrow Vol. 1( 3): 5 - 7.

Aldrigde, R.W; Zenner, D; Williamson, E.J; Muzyamba, M.C; Dlavan, P; Mosca, D; LaiorM.K; Abubakar, I. \& HavwardA.C. (2016). Tuberculosis in Migrants moving from high-incidence to low incidence countries: A Population-based cohort study 519955 Migrates Screened before entry to England, Wales, and Northern Ireland.

Arshad, S., Bavan, L. Gajar,I K., Paget, S.N.J., Baussano, I. (2010). Active screening at the entry for tuberculosis among new immigrants: a systematic review and meta analysis. Eur Respir Journal, 35(6):1336-45. https://doi.org/10.1183/09031936.00054709 PMID: 19840970

Arshad, S; Bavan, L; Gayari, K; Paget, S.N.J \&Bavssano, I. (2010). Active Screening at the entry for Tuberculosis among new Immigrants: a Systemic renew of Meta-analysis. Eur.Respiratory Journal, 35(6) 1336 - 45. https://doi.org/10.1183/09031936.00054709. PMD: 19840970

Blum, C. (2014) Cross-Border Flows Between Nigeria And Benin: What Are the Challenges for Human Security? Peace and Security Series, Friedrich-Ebert-Stiftung:4.retrieved from https://library.fes.de/pdf-files/bueros/nigeria/10883.pdf on the $24^{\text {th }}$ November, 2018 .

Castelli, F \& Sulis, G. (2017) Migration and Infectious diseases. Clinical, Microbiology and Infection (CMI) vol 23(5): 283-289. Doi:httph/www.doi.org/10.1016/j.cmi.2017.03.012

Darkwah, S.A. \& Verter, N. (2014). Determinants of International Migration: The Nigeria Experience. Acta Universitatis Agriculture Et Silvicucherae Mendelianae Brunensis vol. 62(2): $321-327$.

De Haas, H. (2010). Migration and Development: A Theoretical Perspective. International Migration Review, 44: 227 (Cross Ref).

DFID, (2004).Migration in West Africa. DFID Briefing. Development Research Centre on Migration, Globalization and Poverty. Sussex Centre for migration Research...migrants in Development Policies.London: DFID social Development working paper No. Retrieved from https//www.ajol.info.article on $2^{\text {nd }}$ May 2017 at $4.30 \mathrm{pm}$

Dinshak L D.\& Danfulani, A. W.(2018) ECOWAS and Human Security in West Africa: A Review of the Literature. Journal of Humanities and Social Sciences. Volume 23(12):7582 DOI: 10.9790/0837-2312027582 www.iosrjournals.org

Dustmann, C., Fraltini, T. \& Glitz, A. (2007).The Impact of Migration: A Review of the Economic Evidence. CREAM. Retrieved from: www.ucl.ac.uk/ uctpb21/reports/WAFinal-Final.pdf

Eiset, A.H. \& Wejse, C. (2017). Review of Infectious diseases in refugees and asylum seekscurrent status and going forward. Public Health Reviews, 38(22).

Farah, M.G; Meyer, H.E; Selmer, R;\& Blune, G. (2005).Long-term risk of Tuberculosis among Immigrants in Norway.International Journal of Epidemiol, 34(5): 1505-11.

Glove, S; Gott, C.; Loizillon, A.; Portes, J.; Price, R.; Spencer, S.; Srinivason, V.; \& Willis, C. (2001). Migration: An Economic and Social Analysis. RDs Occasional Paper No. 67, London: Home office. 
Hagopion, A.; Thompson, M.; Fordyu, M.; Johnson, K.; Hart, L.G (2004). The Migration of Physicians from sub-Saharan Africa to the United States of America: measures of the Africa brain drain. Human resources for Health, 2:17-26.

Jensen, S.G, Olsen, N.W.; Seersholm N.; Lillebaek, T.; Wilcke, .; Pedersen M.K, et al. (2015) Screening for TB by sputum culture in high-risk groups in Copenhagen, Denmark: a novel and promising approach. Thorax.;70(10):979-83. https://doi.org/10.1136/thoraxjnl-2015-207162 PMID: 26156525

Kahn, K.M.; Collison, S.; Toolman, B.; Wolff, M.\& Clark, S. (2003). Health Consequences of Migration: Evidence from South Africa's Rural Northeast (Agincourt) Paper Presented for Conference on African Migration in Comparative Perspective; Johannesburg, South Africa, 4-7 June.

Kristiansen, M., Myginda,A.\& Krasnik, A (2007). Health effects of Migration. Danish Medical Bulletin,54(1): 46- 27.

Lee, S. E. (1966). Theory of Migration Demography, vol. 3,: 47-87.

Meija, A., Pizurki, H. \& Royston, E. (1979). Physician and Nurse Migration: Analysis and Policy Implications. World Health Organization; France Xiii - 476.

Nunn, A.J.; Wagh, H.U\&Camali, et. al. (1995), Migration and HIV Seropic Valence in Rural Uganda. Population AIDs, 9: 503 - 6.

Olawale, I(2011), ECOWAS and Human Securityp:167.49 Retrieved from http://hdr.undp.org/en/content/human-developmentreport-1994 retrieved at $10.00 \mathrm{am}$ on the $20^{\text {th }}$ November 2017

Pattersson, R. (2003). Screening Immigrants for Infectious diseases. The Lancet Infectious Diseases, 3(ii): 681.

Philip, A.; Vanlandingham, M. Manda-Taylor, L.; \& Hans-petem, K. (2016).Migration and HIV Infection in Malawi.AIDs, 30(13): 2099 - 2005. Doi 10.1097/QAD 0000000000001150.

Piau, J.P., Lagarde, E., vvan der Loeff, S, M.., Enel, C., Holmgren, B., Dray-Spira, R., Pison, G., ..(2003), Mobility and the Spread of Human Immunodeficiency Virus into Rural Areas of West Africa. International Journal of Epidemiology vol 32(5): 744 - 752. http://doi.org/10.1093/ije/dvg111

Pison, G. \&Le Guenno, B.,Legarde,E.,Enel.C\&Seck,C. (1993), Seasonal Migration a risk factor for HIV in Rural Senegal. Journal of Acquired Immunodeficiency Syndrome 6, 196 $-203$.

Ponticiello, A; Sturkenboom, M.C; Simonetti, A; Ortolani, R; Malerba, M. \& Sanduzzi, A. (2005). Deprivation Immigration and Tuberculosis Incidence in Naples, $1996-2000$. European Journal of Epidemiology. 20: 729 - 734.

Taminu, M; Hallermaiam, M. G \&Haider, J. (2011), HIV Related Sexual Behaviour among Migrants and Non-migrant in rural Ethiopia: Role of Rural-Urban Migration in HIV Transmission. International Journal of Biomedical Science 7(4): 245 - 303.

Taminu, M; Hallermaiam, Mitike, G \& Haider, J. (2011), HIV Related Sexual Behaviour among Migrants and Non-migrant in rural Ethiopia: Role of Rural-Urban Migration in HIV Transmission. International Journal of Biomedical Science 7(4): 245 - 303.

Tuite, A.R, Thomas-Bachli, A; Acosta, M; Bhatia, D; Huber, C; \&Petrasek, K. (2018).Infectious disease Implications of Large Scale Migration of Venezuelan Nationals.International Journal Society of Travel Medicine: 1 -8. Doi.10.1093/tm/tay077.

UNDP (1994).New Dimension of Human Security: Human Development Report. New York: Oxford University Press. 
United Nations Development Program, Narazani, E. (2012). Migration and Infant Mortality in Albania. https://dx.doi.org/10.2139/ssm.2189601

United Nations Development Programme (UNDP) (2009). International Migrant Stock: The2008 Revision. UNDP Database.

Vietti, F (2003). Human Insecurity: Understanding International Migration from a Human Security Perspective. Journal on Migration and Human Security. Vol. (1): 17 - 31.

Vignier, N. \& Bouchaud, O. (2018).Travel, Migration and Emerging Infectious diseases.The Journal of International Federation of Clinical Chemistry and Laboratory Medicine (EJIFCC) vol. 29(3): 175 - 179.

Whaba, J. (2007). Return to Overseas work Experience: The Case of Egypt in Ozden, C. Schit, M. (eds), International Migration, Economic Development and Policy. Washington D.C: World Bank and Palgrave Macmillan, Washington D.C.

Zimmerman, C., Kiss, L. \& Hossain, M. (2011). Migration and Health a Framework for $21^{\text {st }}$ Century Policy-making Plos Med 8(5): e1001034.

Zuma, K.,Gouws, E.; Williams, B. \& Lurie, M.; (2003), Risk Factors for HIV Infection among Women in Carletonville, South Africa: Migration Demography and Sexually Transmitted Diseases. International Journal of STD \& AIDs 14:814 - 817. 